\title{
PLANEJAMENTO PARTICIPATIVO DA PAISAGEM NA CIDADE DIGITAL: ANÁLISE DE POTENCIALIDADES EM CURITIBA, PARANÁ
}

\section{LANDSCAPE PARTICIPATORY PLANNING IN THE DIGITAL CITY: ANALYSIS OF THE POTENTIALITIES IN CURITIBA, PARANÁ}

\section{Regina Maria Martins de Araujo Klein}

Doutoranda em Gestão Urbana PPGTU pela Pontifícia Universidade Católica - PUCPR, Paraná (Brasil). Docente de Arquitetura pela Pontifícia Universidade Católica - PUCPR, Paraná (Brasil). E-mail: reginamma@gmail.com

\section{Letícia Peret Antunes Hard}

Doutora em Engenharia Florestal pela Universidade Federal do Paraná - UFPR, Paraná (Brasil). Professora pela Pontifícia Universidade Católica do Paraná - PUCPR, Paraná (Brasil).

E-mail: 1.hardt@pucpr.br

Denis Alcides Rezende

Doutor em Engenharia de Produção pela Universidade Federal de Santa Catarina - UFSC, Santa Catarina (Brasil). E-mail: denis.rezende@ pucpr.br 


\section{PLANEJAMENTO PARTICIPATIVO DA PAISAGEM NA CIDADE DIGITAL: ANÁLISE DE POTENCIALIDADES EM CURITIBA, PARANÁ}

\section{RESUMO}

As tecnologias e serviços aplicados em ambiente virtual oferecem alternativas de inclusão dos cidadãos no processo de qualificação de cenas urbanas, sendo, portanto, oportunos para a prevenção da falta de articulação da temática paisagística na esfera da administração pública. Diante desses pressupostos, a questão central da pesquisa é voltada à interpretação das reais possibilidades de incorporação do tema e da factual participação da população na gestão municipal por meio de recursos tecnológicos de informação. Nesse contexto, o objetivo geral da investigação é analisar o potencial do planejamento participativo da paisagem na cidade digital. Assim, é apoiada em estudo documental sobre a realidade de Curitiba, Paraná. A unidade de observação abrangeu a legislação interveniente na composição das áreas verdes, definidas como recortes relevantes dos componentes paisagísticos da malha urbanizada. As normas legais foram associadas tanto a parâmetros qualiquantitativos de elementos morfológicos e compositivos, quanto a perspectivas de interface com a comunidade. Os resultados obtidos demonstram a insuficiência de efetiva integração dos citadinos nos atuais processos de ordenamento desses espaços na capital paranaense. Não obstante as limitações dos procedimentos adotados, conclui-se pela existência de capacidade de ampliação dessa conexão no âmbito da cidade digital. Este fato é diagnosticado pela identificação de oportunidades de intensificação do envolvimento virtual dos munícipes e de diversidades de opções tecnológicas para esta finalidade.

Palavras-chave: Paisagem urbana. Tecnologia da informação. Interface com cidadão. Gestão municipal. Áreas verdes. 


\title{
LANDSCAPE PARTICIPATORY PLANNING IN THE DIGITAL CITY: ANALYSIS OF THE POTENTIALITIES IN CURITIBA, PARANÁ
}

\begin{abstract}
The technologies and services applied in a virtual environment offer alternative inclusion of citizens in the urban scenes qualification process, it is therefore desirable for the prevention of lack of articulation of landscape theme in the public administration sphere. Given these assumptions, the central question of the research focused on the interpretation of the incorporation possibilities real theme and factual participation of the population in municipal management through technological information resources. In this context, the main research objective is to analyze the potential of participatory planning of the landscape in the digital city. Thus, it is supported by documentary study on the reality of Curitiba, State of Parana. The observation unit covered the intervening legislation in green areas composition, defined as relevant clippings of landscape components of the urban area. Legal standards were associated with both qualitative and quantitative parameters of morphological and compositional elements as the interface with the community perspectives. The results demonstrate the lack of effective integration of urban dwellers in the current planning processes of these spaces in Curitiba. Notwithstanding the procedures adopted limitations, the conclusion indicates existence of capacity expansion in this connection within the digital city. This fact diagnosed by identifying enhancement opportunities of citizen's virtual involvement and technological diversity options for this purpose.
\end{abstract}

Keywords: Urban landscape. Information technology. Interface with citizen. Municipal management. Green areas. 


\section{INTRODUÇÃO}

As paisagens urbanas podem ser entendidas como representações da existência cotidiana, atuando como narrativas formais do contexto histórico dos citadinos (Relph, 2008). A partir desse entendimento, pode-se explorar a identidade social por meio da imagem paisagística, a qual, como uma mídia dinâmica, revela um conjunto de práticas culturais e econômicas que registram memórias e as corporificam em cenas das cidades (Mitchell, 2002).

A gestão urbana pode favorecer a sustentação de cenários memorativos, dando continuidade física a tradições socioculturais e potencializando o endereçamento de significados à cidade (Cosgrove, 2006). Assim, entende-se a paisagem como um projeto político, não apenas de caráter estético ou de preservação histórica, mas, sobretudo, de conexão orgânica entre habitantes e espaço habitado. Por outro lado, a pluralidade dos componentes que caracterizam as cenas urbanas envolve a sobreposição de vários instrumentos legais e diferentes órgãos competentes para a sua gestão.

Frequentemente, essa complexidade leva à insuficiência de mecanismos específicos de planejamento e monitoramento paisagístico. Como consequência, os panoramas das urbes têm se transformado em constantes resultados automáticos da aplicabilidade das leis que regulamentam a ocupação do solo e o uso dos recursos ambientais (Olwig, 2013). Logo, a percepção do cidadão de espaço qualificado não é mensurada como variável de planejamento, provocando-se, com frequência, a quebra de relações identitárias entre pessoas e espaços, ao serem promovidos cenários vazios de significados (Tuan, 2012).

A paisagem se apreende, predominantemente, pelo nível de excelência das suas características visuais, que não só envolve a diversidade de elementos da sua composição, mas, principalmente, a multiplicidade de interpretações e percepções individuais dos seus observadores. Nessa condição, a sua qualificação depende da adoção de métodos baseados em juízos de valor e, logo, da inserção dos usuários no sistema de planejamento e avaliação (Hardt, 2004; Macedo, 2010).

Nesse âmbito, as tecnologias e atividades relacionadas à cidade digital e, em especial, à inclusão do cidadão, são oportunas à articulação efetiva da temática da 
paisagem na gestão municipal. Um dos potenciais dessa tipologia urbanística reside na promoção de um ambiente de aplicações e serviços para melhoria da comunicação entre munícipes e governo local (Mendes, Bottoli \& Breda, 2010). A partir da coleta, estruturação e disponibilização de informações, os indivíduos podem interagir entre si e com os governantes, interligando-se na rede virtual de determinado território, por meio dos subprojetos de cidade digital estratégica (Rezende, 2012 a, b).

Considerando a aplicabilidade de tecnologias da informação para a integração do cidadão ao processo de qualificação paisagística, o objetivo geral deste artigo é analisar o potencial do planejamento participativo da paisagem na cidade digital. Nesse sentido, é realizado um estudo documental na cidade de Curitiba, Paraná, com a seleção da vegetação como elemento de composição paisagística. Tal procedimento pode ser justificado pelo fato de as áreas verdes constituírem importante fator para a elevação da qualidade de cenários urbanizados (Hardt, 2000). Por sua vez, a motivação para a pesquisa na capital paranaense é decorrente do seu relevante histórico de planejamento e dos seus instrumentos legais de ordenamento urbanístico indutores de um espaço frequentemente associado, pela mídia, a questões ambientais, em especial àquelas áreas (IPPUC, 2016).

Mesmo com a representatividade desses espaços no desenho urbano de Curitiba, a medição atual de sua qualidade tende a ser simplificada no parâmetro "área por habitante", ou seja, ainda não foram consideradas avaliações paisagísticas que incorporem componentes cognitivos, representados pela percepção humana (Hardt, 2004). Assim, as políticas públicas têm se limitado à dimensão material, enquanto o endereçamento simbólico não é quantificável (Sgard, 2012). Nessa conjuntura, este artigo busca nos conceitos de cidade digital, os caminhos para a incorporação de aspectos da imaterialidade da paisagem na gestão municipal.

\section{REFERENCIAL TEÓRICO}

A paisagem urbana pode ser entendida como uma constante construção, resultante de processos de inter-relação entre sociedade e espaço, tendo uma dimensão material - 
realizações e práticas - e outra imaterial - estética, moral e simbólica (Sgard, 2012). Sob essa ótica, a argumentação teórica deste estudo parte do princípio de que os componentes paisagísticos das cidades induzem a formação de elos entre habitantes e território habitado, os quais podem ser reforçados pela inclusão dos cidadãos pelas tecnologias da informação.

\section{Conexão entre habitantes e território habitado}

Interpretando os panoramas urbanos, é possível explicar as interações estabelecidas entre sociedade e território, este considerado como área sob a posse de determinado grupo (Haesbaert, 2004). A apropriação afetiva da paisagem é o centro das relações simbólicas que resultam no sentimento de pertencimento a um espaço, o qual passa, segundo Tuan (2012), a ser conceituado como "lugar". Sgard (2012) ressalta que a unidade de um grupo se expressa no cenário que ele reconhece como comum. A beleza cênica atua como indicador de valores morais de coletividades estáveis; assim, interessa às comunidades serem distinguidas pela qualidade de cenas dos seus locais de vivência, não apenas na sua dimensão estética, mas também nas possibilidades de experiências sensoriais (Cosgrove, 2006).

Dada a diversidade de elementos antrópicos e naturais que se relacionam na composição paisagística, Hardt (2004) interpreta que a avaliação da sua qualidade é de difícil definição em termos absolutos, sendo necessário o estabelecimento de critérios baseados em juízos de valor. Macedo (2010) também comenta que a leitura de uma paisagem acontece dentro de uma escala e segundo cada observador. Dorigo e Ferreira (2015) alertam que o conhecimento da percepção pessoal e coletiva dos diversos atores é imprescindível à melhoria qualitativa do ambiente urbanizado.

Nessa perspectiva, a qualificação paisagística está relacionada a processos perceptuais, especialmente quanto ao entendimento de como a imaginação e a memória captam e organizam as informações e as transformam em categorias cognitivas. A realidade apreendida é individual e vinculada à agregação de valores culturais e sociais, a partir de dois filtros (Hardt, 2000):

a) biofísicos - estímulos sensitivos, principalmente condicionados por características de visibilidade, de posicionamento e de compleição do 
observador, bem como por condições de iluminação e de barreiras visuais do ambiente, dentre outras;

b) condutuais - reações cognitivas do indivíduo, em especial culturais, sociais, econômicas e psicológicas - emocionais e afetivas -, relacionadas ao processo formativo da sua personalidade.

A reunião desses aspectos sugere a complexidade da gestão da paisagem urbana, sob a responsabilidade de diferentes atores, envolvendo uma diversidade de elementos. Seu planejamento, projeto ou resultado automático da dinâmica urbanística têm variados impactos sobre a percepção de qualidade dos citadinos, cuja participação é essencial no processo, no intuito da sua conexão com o cenário que habitam.

\section{Inclusão do cidadão pelas tecnologias da informação}

A cidade digital pode ser entendida como resultante da aplicação dos recursos da tecnologia da informação na gestão do município e também na disponibilização de dados e de serviços aos munícipes. Ainda pode ser definida como o ambiente ou plataforma de rede digital criada no território, que interliga sistemas tecnológicos avançados para conectar serviços públicos, bens, marcas, escolas, organizações do terceiro setor, empresas, micro e macrocomunidades de pessoas. Dessa maneira, disponibiliza informações em diversas ordens e padrões com o propósito de desenvolver as potencialidades da sociedade de informações e transformar o cidadão em ator e protagonista de outra realidade: virtual (Guerreiro, 2006).

As cidades digitais também podem ser conceituadas como aquelas que coletam e organizam informações digitais das correspondentes e proporcionam um espaço de informação pública para as pessoas interagirem umas com as outras por meio da internet (Ishida, 2012). Mossberger, Tolbert e McNeal (2008) explicam que podem ser habitadas por cidadãos digitais com a sua capacidade de participação na sociedade online.

Para Rezende (2012b), a cidade digital estratégica é um projeto mais abrangente, indo além da oferta de acesso à internet por intermédio de recursos convencionais de telecomunicações. Pode ser entendida como a aplicação da tecnologia da informação na 
gestão do município e também na disponibilização de dados e serviços aos munícipes, embasada em estratégias municipais.

Com base nesses conceitos, destaca-se, nesta subseção, o potencial desse ambiente na inserção do citadino, como qualificador do espaço, no processo de planejamento da paisagem. A ideia de integração do cidadão entra em sinergia com o entendimento de Nava e Dávila (2005), que destacam a inclusão social, a democracia e a cooperação em rede como fundamentos essenciais da cidade digital, a partir de ambientes específicos. No mesmo sentido, enquadram-se os conceitos de Besselaar e Beckers (2009) e de Rezende (2012a), relacionando as cidades digitais à coleta e organização de dados, oferecendo um espaço informacional e interativo para os seus atores.

Para Albertin e Albertin (2012), a tecnologia da informação pode ser entendida como o conjunto de hardware, software e pessoas envolvidas na obtenção, armazenamento, tratamento, comunicação e disponibilização de dados e conhecimento. Possibilitando a melhoria da capacidade de gestão municipal ao acelerar processos e reestruturar serviços, permite, de um lado, o aumento da produtividade e o aperfeiçoamento da qualidade das ações governamentais, e, de outro, as interações mais dinâmicas entre os cidadãos e a administração pública.

Rossetti e Morales (2007) afirmam que a tecnologia da informação tem sido cada vez mais empregada com diferentes fins, sendo gerada a partir do conhecimento das pessoas, visando à sua sistematização e divulgação. Essa possibilidade de organização de estruturas cognitivas que representam determinada realidade (Cardoso \& Machado, 2008) ou que compreendem verdades resultantes de interpretações pessoais a partir de visões próprias de mundo, é essencial para a qualificação paisagística, por constituir um exercício predominante de ordenamento de percepções individuais (Hardt, 2004).

Entretanto, a cidade digital vai além da prática de incluir digitalmente os usuários na rede mundial de computadores (Rezende, 2012b). Para a sua adequada implantação, exige a formalização, pelas organizações públicas envolvidas, dos seguintes processos de planejamento: estratégico do município (PEM), com a definição de objetivos e metas por meio de funções ou temáticas particulares, de informações municipais (PIM) e da tecnologia da informação (PTI). Os modelos de dados das funções ou temáticas são os principais produtos do PIM, como pré-requisitos para o planejamento dos sistemas de 
informações (SI) e de conhecimentos (SC), bem como dos perfis de recursos humanos necessários, sejam dos gestores locais, dos servidores municipais ou dos munícipes. O PTI possibilita o ordenamento dos recursos da tecnologia da informação e respectivos serviços oferecidos pelo município aos cidadãos (Rezende, 2012b).

Cândido e Araújo (2003) destacam como principais tecnologias da informação utilizadas para implementação e viabilização da gestão do conhecimento, as videoconferências, o growpware (software colaborativo), os painéis eletrônicos, os grupos de discussão, as bases de dados on-line, a internet, as intranets, os sistemas especialistas, os agentes inteligentes de pesquisa, o data warehouse (armazenamento de dados), o data mining (mineração de dados) e o gerenciamento eletrônico de documentos. Por meio de recursos tecnológicos e computacionais para guarda, geração e uso da informação e do conhecimento, a tecnologia está fundamentada nos seguintes componentes: hardware e seus dispositivos e periféricos; software e seus recursos; sistemas de telecomunicações; e gestão de dados e informações (O’Brien, 2011; Rezende \& Abreu, 2013; Turban, Rainer \& Potter, 2007).

A partir dessas possibilidades, este artigo expõe a análise das formas pelas quais as interfaces atuais entre o observador de cenas urbanas e o seu planejamento podem ser ampliadas por meio de tecnologias da informação no contexto da cidade digital. Dessa forma, as alternativas de gestão do conhecimento do cidadão, como usuário, permitem a disseminação de melhores práticas em relação à temática da paisagem na gestão municipal.

\section{MÉTODOS E TÉCNICAS DE PESQUISA}

Para interpretação da aplicabilidade de tecnologias da informação com vistas à integração do cidadão ao processo de qualificação da paisagem, foram adotados métodos exploratórios, descritivos e analíticos (Gil, 2008), associados a técnicas de pesquisa bibliográfica e documental A unidade de observação correspondeu à legislação do município de Curitiba interferente na composição das áreas verdes da cidade, na condição de relevantes componentes paisagísticos da malha urbanizada (Hardt, 2000). 
Para o alcance do objetivo geral da investigação, suas duas fases principais foram estruturadas a partir do protocolo apresentado no Quadro 1.

Quadro 1: Protocolo de pesquisa para aplicabilidade de tecnologias da informação para integração do cidadão no processo de qualificação da paisagem.

\begin{tabular}{|c|c|c|c|}
\hline Macrovariável & Fontes / autores centrais & Questão & Unidade de medição \\
\hline $\begin{array}{c}\text { Interface com o } \\
\text { cidadão }\end{array}$ & $\begin{array}{l}\text { Albertin \& Albertin (2012) } \\
\text { Cândido \& Araújo (2003) } \\
\text { Hardt (2000, 2004) } \\
\text { Lamas (2014) } \\
\text { Nava \& Dávila (2005) } \\
\text { Rezende (2012a,b) } \\
\text { Rossetti \& Morales (2007) }\end{array}$ & $\begin{array}{c}\text { Os procedimentos } \\
\text { existentes na } \\
\text { aplicabilidade das leis } \\
\text { relativas às áreas } \\
\text { verdes permitem } \\
\text { interfaces com o } \\
\text { cidadão quanto à } \\
\text { qualificação de áreas } \\
\text { verdes? }\end{array}$ & $\begin{array}{l}\text { Existência de interface com o } \\
\text { cidadão na aplicabilidade da lei } \\
\text { (sim/não) } \\
\text { Probabilidade de aplicação de } \\
\text { tecnologia da informação para } \\
\text { estabelecimento de conexão com } \\
\text { o cidadão } \\
\text { (sim/não) } \\
\text { Possibilidade de contribuição do } \\
\text { cidadão com a base de dados de } \\
\text { qualificação da paisagem } \\
\text { (sim/não) }\end{array}$ \\
\hline
\end{tabular}

Fonte: Elaborado a partir do objetivo geral da pesquisa.

A coleta e análise dessas normas legais constituiu a primeira fase da investigação. O inventário de dados aconteceu por meio de pesquisa bibliográfica e documental nos sites oficiais da Prefeitura Municipal de Curitiba que divulgam o arcabouço legal do município e seu processo de alteração e atualização. A seleção de leis e decretos partiu dos princípios de sua determinação direta de características compositivas do espaço, especialmente de áreas verdes, ou de sua influência sobre parâmetros qualiquantitativos (área, variedade de espécies, porte, forma, cor e textura), independente da verificação do seu cumprimento.

Entre 1975 e 2015, foram identificadas no arcabouço legal de Curitiba, 19 normativas de regulamentação das áreas verdes da cidade e, entre elas, 14 com influência morfológica. Na segunda fase da pesquisa, as normas ressaltadas foram examinadas à procura das diretivas de ação da prefeitura para o cidadão ou deste para o órgão gestor, definindo a existência ou potencial de interface com o cidadão. 
Considerando o escopo de cada norma legal analisada, foram apontadas oportunidades de ampliação das interfaces com a população na cidade digital, por meio de tecnologias da informação, em concordância com as destacadas por Cândido e Araújo (2003), quais sejam: painel eletrônico, grupos de discussão e base de dados e serviços on-line. O Quadro 2 expõe as oportunidades visualizadas a partir de cada opção tecnológica.

Quadro 2: Oportunidades de aplicação da tecnologia da informação à ampliação da interface com a população na cidade digital.

\begin{tabular}{|c|c|}
\hline $\begin{array}{l}\text { Tecnologia da } \\
\text { informação }\end{array}$ & Oportunidades de ampliação da interface \\
\hline Painel eletrônico & $\begin{array}{l}\text { Quando existe a possibilidade de incorporar a percepção da população sobre } \\
\text { determinado tema. }\end{array}$ \\
\hline Grupos de discussão & Quando a temática permite a configuração de um fórum. \\
\hline Base de dados on-line & $\begin{array}{l}\text { Quando o escopo aborda itens de interesse à complementação do sistema de informações } \\
\text { municipais. }\end{array}$ \\
\hline Serviços on-line & $\begin{array}{l}\text { Quando a troca de ação entre o citadino e o órgão gestor pode acontecer em plataforma } \\
\text { digital. }\end{array}$ \\
\hline
\end{tabular}

Fonte: Elaborado com base em Cândido e Araújo (2003).

Conforme antes mencionado, as opções temática e geográfica do presente estudo incidiram sobre os espaços verdes da capital paranaense. Descrevendo brevemente o processo de planejamento de Curitiba, a próxima subseção é voltada à compreensão da paisagem como resultante da legislação municipal relacionada ao meio ambiente e ao uso e ocupação do solo.

\section{Contextualização da área de estudo}

Os primeiros marcos legais de impactos na morfologia urbana de Curitiba datam da década de 1880, acompanhando as transformações impulsionadas, principalmente, pelas conexões proporcionadas pela chegada da ferrovia. Em 1985, a atualização do Código de Posturas passou a dispor sobre larguras mínimas das ruas, volumetria das edificações, alinhamento predial e aberturas nas fachadas, entre outras medidas 
destinadas à organização espacial. Vinte anos depois, diretrizes de hierarquização viária e restrições de uso do solo foram embriões de um zoneamento preliminar, com principais efeitos nas ruas Barão do Rio Branco e XV de Novembro, bem como no entorno da Praça Tiradentes (Barz, Boschilia, Hladczuk \& Sutil, 1997).

Invariavelmente, os grandes eixos viários foram estruturantes na evolução do processo de planejamento curitibano. Em 1920, marcaram a expansão urbana na direção sul, promovendo a ocupação da região conhecida, à época, como "Cidade Nova". O "Plano de Avenidas", em especial, estabeleceu princípios de circulação e conexão, valorizando espaços livres de praças, jardins e parques públicos (Trindade, 1997).

Na década de 1940, as inundações que atingiam a área central condicionaram o desenvolvimento do denominado "Plano Agache", no qual foram previstos centros funcionais e de recreação, incluindo o Parque Barigui (Trindade, 1997).

Em 1960, teve início uma nova concepção de planejamento ("Plano Serete"), apoiada no conceito de funcionalização dos espaços e na criação de novos locais de encontro para a população. Nesse escopo, foram privilegiados o transporte coletivo e o traçado de um sistema viário fundamentado em vias estruturais, prioritárias e conectoras. Em paralelo, foi determinada a implantação dos parques lineares ao longo dos principais rios urbanos, associando as áreas de lazer, esporte e recreação à proteção do sistema natural de drenagem (Barz et al., 1997).

Esses conceitos, regulamentados pela Lei Municipal $n^{\circ} 5.234$, de 10 de dezembro de 1975 (Curitiba, 1975), que modificou o anterior zoneamento urbano, deram origem aos denominados "Setores Especiais" (de Áreas Verdes, de Fundos de Vale e da Cidade Industrial), definiram as questões ambientais como determinantes no planejamento urbano da capital paranaense. Como síntese, o Quadro 3 apresenta a evolução das principais normas legais municipais que influenciaram a disposição das áreas verdes de Curitiba, enquanto elemento da paisagem urbana. 
Regina Maria Martins de Araujo Klein, Letícia Peret Antunes Hard e Denis Alcides Rezende

Quadro 3: Evolução da principal legislação municipal sobre áreas verdes de Curitiba - 1975 a 2015.

\begin{tabular}{|c|c|c|c|}
\hline Cronologia & Decreto & Lei & Abordagem \\
\hline 1975 & & 5.234 & Criação dos Setores Especiais \\
\hline 1976 & 400 & & Regulamentação dos Setores de Preservação de Fundos de Vale \\
\hline 1978 & 226 & & Planejamento da arborização urbana \\
\hline \multirow{2}{*}{1988} & & 7.230 & Obrigatoriedade do plantio de vegetação em áreas não edificáveis \\
\hline & 471 & & Disposições sobre parques municipais \\
\hline \multirow{3}{*}{1991} & & 7.622 & Utilização de recuos como áreas verdes \\
\hline & & 7.651 & Exigência de plantio de árvores nos passeios \\
\hline & & 7.833 & Instituição da política ambiental do município \\
\hline 19093 & & 8.353 & Monitoramento da vegetação arbórea \\
\hline \multirow{5}{*}{2000} & & 9.800 & Revisão do zoneamento, uso e ocupação do solo \\
\hline & & 9.804 & Criação do Sistema Municipal de Unidades de Conservação \\
\hline & & 9.805 & Setor Especial do Anel de Conservação Sanitário-ambiental \\
\hline & & 9.806 & Instituição do Código Florestal Municipal \\
\hline & 195 & & Disposições sobre Setor Especial de Áreas Verdes da CIC \\
\hline 2002 & 673 & & Criação do Setor Especial do Parque Natural Municipal Tanguá \\
\hline 2008 & 473 & & Definição de espécies florestais exóticas invasoras \\
\hline 2009 & 1.181 & & Declaração de árvores imunes ao corte \\
\hline 2010 & & 13.519 & Instituição de campanha de incentivo à arborização \\
\hline 2015 & & 14.771 & Revisão do plano diretor municipal \\
\hline
\end{tabular}

Fonte: Leis Municipais (2016)

Notas: $\quad$ Negrito $=$ legislação selecionada para análise específica $($ ver seção 4)

$\mathrm{CIC}=$ Cidade Industrial de Curitiba

Os instrumentos de incentivo à conservação das áreas verdes foram gradativamente compondo o arcabouço legal do município: regulamentação dos Setores Especiais de Preservação de Fundos de Vale (Decreto Municipal n ${ }^{\circ}$ 400/1976), instituição do Plano de Arborização Urbana (Decreto Municipal no 226/1978), obrigatoriedade de plantio de vegetação em áreas não edificáveis (Lei Municipal $n^{\circ}$ 7.230/1988) e disposição sobre parques urbanos (Decreto Municipal $n^{\circ}$ 471/1988) (Curitiba, 1976; 1978; 1988a,b). 
Entretanto, foi a partir da década de 1990 que a legislação ambiental foi intensificada, antes com especificações sobre utilização de recuos do alinhamento predial como área verde (Lei Municipal $n^{\circ}$ 7.622/1991) e com a exigência de plantio de árvores em passeios (Lei Municipal no 7.651/1991). Paralelamente, foi regulamentada a política específica pela Lei Municipal n 7.833/1991, estabelecendo instrumentos para a promoção e controle da qualidade do meio ambiente. Cabe destaque, ainda, à Lei Municipal n 8.353/1993, que versa sobre o monitoramento da vegetação arbórea (Curitiba, 1991a, b, c; 1993).

O ano 2000 foi marcado pela consolidação de vários desses princípios, incorporados pela revisão do zoneamento do uso e ocupação do solo (Lei Municipal $\mathrm{n}^{\circ}$ 9.800/2000). Também houve a regulamentação do Sistema Municipal de Unidades de Conservação (Lei Municipal n 9.804/2000), a criação do Setor Especial do Anel de Conservação Sanitário Ambiental (Lei Municipal $n^{\circ}$ 9.805/2000) e a instituição do Código Florestal (Lei Municipal nº.806/2000) (Curitiba, 2000 a, b, c, d).

Nessa mesma década, outros dispositivos legais foram aprovados visando aspectos localizados de preservação e conservação. Como exemplos, foram legisladas as áreas verdes da Cidade Industrial (Decreto Municipal no 195/2000) e o Parque Tanguá (Decreto Municipal n 673/2002) (Curitiba, 2000e; 2002).

Mais tarde, outras disposições da legislação determinaram as espécies florestais consideradas como exóticas invasoras (Decreto Municipal $n^{\circ}$ 473/2008) e imunizaram algumas árvores ao corte (Decreto Municipal nº 1.181/2009). Também foram instituídas campanhas permanentes de incentivo à arborização de logradouros (Lei Municipal $n^{\circ}$ 13.519/2010) (Curitiba, 2008; 2009; 2010).

Recentemente, várias premissas foram referendadas ou atualizadas pela revisão do plano diretor municipal, visando

propiciar melhores condições para o desenvolvimento integrado, harmônico e sustentável de Curitiba com a Região Metropolitana, sendo o instrumento básico, global e estratégico da política de desenvolvimento urbano, determinante para todos os agentes, públicos e privados. (Lei Municipal $\left.n^{\circ} 14.771 / 2015\right)\left(\right.$ Curitiba, 2015, artigo $4^{\circ}$ ).

Revista de Gestão e Secretariado-GeSec, São Paulo, v. 7, n. 3, p 226-252, set./dez. 2016. 


\section{APRESENTAÇÃO E ANÁLISE DOS RESULTADOS}

A pesquisa documental da legislação vigente evidencia uma base de dados on-line do arcabouço legal do município integrada com diversas temáticas de gestão, podendo ser acessada por qualquer usuário de internet. Porém, assim como as outras interfaces existentes no processo de aplicação das leis intervenientes na paisagem, trata-se de um serviço virtual com direção única: da instituição pública para o cidadão. Ou seja, ainda não foram estabelecidos caminhos para que o munícipe contribua, de forma sistematizada, na alimentação de um sistema de conhecimento que possibilite melhores práticas de planejamento dos cenários da cidade.

Esse sentido unidirecional de transmissão da informação vem ao encontro das preocupações de Mendes, Bottoli e Breda (2010) acerca da necessidade de melhoria da comunicação entre cidadãos e governantes. Além disso, contraria uma condição básica, imposta por Rezende (2012b), para a configuração de uma cidade digital, relacionada à superação do simples acesso às informações urbanísticas por meio da internet, alcançando elevado nível participativo.

Mesmo diante dos benefícios urbanísticos oriundos dos avanços da tecnologia (Mossberger, Tolbert \& Franco, 2013), os recursos tecnológicos existentes em Curitiba também não permitem a articulação entre órgãos gestores que compartilham a temática da paisagem e seus componentes são geridos separadamente, com sobreposição de competências e normas. Secchi (2009) alerta que os novos modelos de gestão e de relação do Estado com a sociedade ainda preservam características burocráticas básicas, com tendência à formação de políticas simbólicas e manipuladoras da percepção do público, dificultando a compreensão dos cidadãos acerca das realidades e perspectivas do processo de urbanização.

Todas as principais normas legais (ver Quadro 3) que tratam das áreas verdes de Curitiba influenciam, de alguma forma, a sua paisagem. Em relação à morfologia urbana, percebe-se que a legislação avaliada tem ampla abrangência sobre esses locais, em diferentes escalas, delimitando glebas a serem preservadas e conservadas, incentivando a inserção de vegetação em espaços livres e fornecendo diretrizes de arborização para passeios e recuos prediais. Seus principais rebatimentos paisagísticos 
residem no potencial de configuração de zonas verdes na dimensão territorial (escala da cidade - Lamas, 2014) e em áreas vegetadas na dimensão urbana (escala do bairro Lamas, 2014) (Quadro 4). A princípio, essas diferenças escalares de reprodução espacial possibilitam visões complementares do ambiente urbanizado, com ampliação do senso perceptivo das estruturas da cidade e consequente elevação dos graus de legibilidade da sua imagem (Lynch, 2011).

Quadro 4: Legislação de áreas verdes com interferência na morfologia urbana de Curitiba.

\begin{tabular}{|c|c|c|c|c|c|c|c|c|c|c|c|c|c|c|c|c|}
\hline Elementos morfológicos & & & 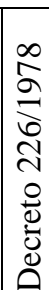 & 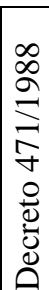 & 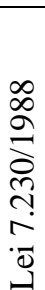 & 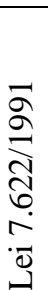 & $\begin{array}{l}\bar{\sigma} \\
\bar{\sigma} \\
\bar{\sigma} \\
i \\
\overline{0} \\
\end{array}$ & 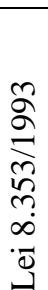 & 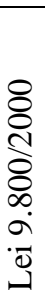 & 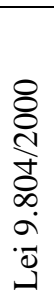 & 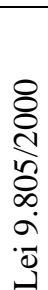 & 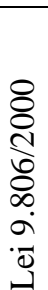 & 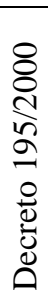 & 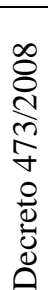 & 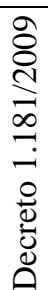 & 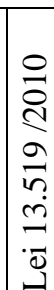 \\
\hline $\begin{array}{l}\text { Dimensão territorial - } \\
\text { escala urbana }\end{array}$ & $\begin{array}{l}\text { Grandes } \\
\text { verdes }\end{array}$ & zonas & & & & & & & & & & & & & & \\
\hline $\begin{array}{l}\text { Dimensão urbana - } \\
\text { escala do bairro }\end{array}$ & $\begin{array}{l}\text { Pequenas } \\
\text { vegetadas }\end{array}$ & áreas & & & & & & & & & & & & & & \\
\hline
\end{tabular}

Fonte: Elaborado com base em leis municipais (2016) e nas dimensões morfológicas propostas por Lamas (2014).

Notas: com interface sem interface

$\mathrm{Na}$ composição das áreas verdes, os impactos da legislação são mais frequentes nos parâmetros quantitativos, na delimitação de locais a serem arborizados e na definição ou proibição de espécies vegetais influentes em padrões qualitativos, como cores e texturas dos espaços (Quadro 5). 
Quadro 5: Legislação de áreas verdes com interferência na composição da paisagem de Curitiba.

\begin{tabular}{|c|c|c|c|c|c|c|c|c|c|c|c|c|c|c|c|}
\hline Parâmetros & & 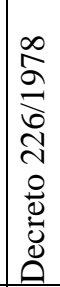 & 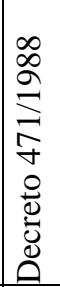 & 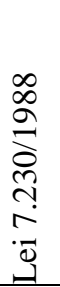 & 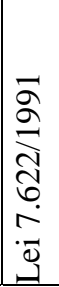 & 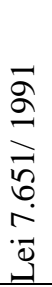 & 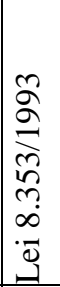 & 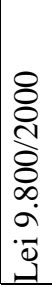 & 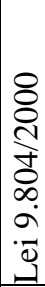 & 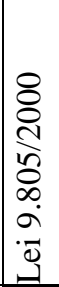 & 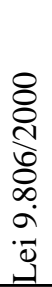 & 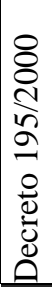 & 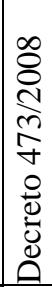 & 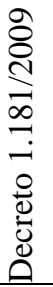 & 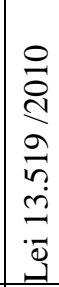 \\
\hline \multirow{3}{*}{ Quantitativos } & Área (ha) & & & & & & & & & & & & & & \\
\hline & Variedade de espécies $\left(\mathrm{n}^{\circ}\right)$ & & & & & & & & & & & & & & \\
\hline & Porte $(\mathrm{h})$ & & & & & & & & & & & & & & \\
\hline \multirow{3}{*}{$\begin{array}{l}\text { Qualitativos } \\
\text { (Perceptivos) }\end{array}$} & Forma & & & & & & & & & & & & & & \\
\hline & Cor & & & & & & & & & & & & & & \\
\hline & Textura & & & & & & & & & & & & & & \\
\hline
\end{tabular}

Fonte: Elaborado com base em leis municipais (2016) e em parâmetros morfológicos quantitativos e qualitativos propostos por Lamas (2014).

Notas: $\quad \square \quad \begin{aligned} & \text { com interface } \\ & \square\end{aligned}$

Aos aspectos morfológicos de quantidade e qualidade, Lamas (2014) associa outros de caráter funcional, figurativo, comunicativo e orientativo. Nesse complexo sistema urbano, Dorigo e Ferreira (2015) evidenciam que as áreas verdes se posicionam entre os mais importantes espaços das cidades, inclusive pela minimização de diferenciados impactos provocados pelas atividades humanas.

Como a qualificação dessas áreas está relacionada às formas como seus usuários as percebem, a combinação dos parâmetros quantitativos e qualitativos em resultados positivos ou negativos de avaliação de qualidade só pode ser mensurada por meio da interface com o cidadão.

Hardt $(2000,2004)$ enumera várias técnicas de análise da qualidade paisagística a partir da interpretação subjetiva de cenas urbanas, sendo a maior parte delas compatível com ambientes virtuais, tornando-as potencialidades à interação com a população. Na legislação avaliada, contudo, são limitadas as atuais conexões entre os usuários e a composição da paisagem. Em sua maioria, são serviços com potencial de serem prestados on-line e as informações trocadas podem ser sistematizadas para estruturação de uma base de dados também em rede (Quadro 6). 
Planejamento Participativo da Paisagem na Cidade Digital: Análise de Potencialidades Em Curitiba, Paraná

Quadro 6: Interfaces existentes com o cidadão na aplicabilidade das leis intervenientes na composição e qualificação da paisagem de Curitiba.

\begin{tabular}{|c|c|c|c|c|c|c|c|c|c|c|c|c|c|c|c|}
\hline Legislação & 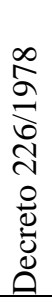 & 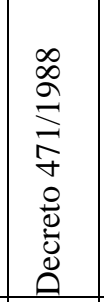 & 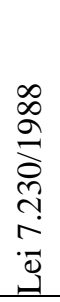 & 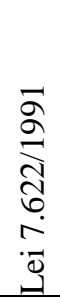 & 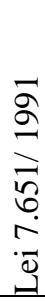 & 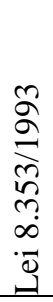 & 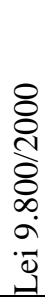 & 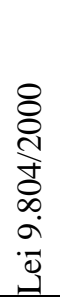 & 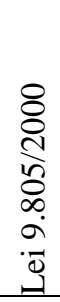 & 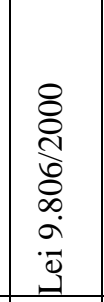 & 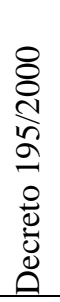 & 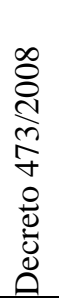 & 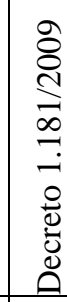 & & 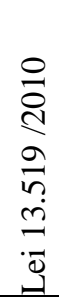 \\
\hline $\begin{array}{l}\text { Interfaces com o } \\
\text { cidadão }\end{array}$ & & 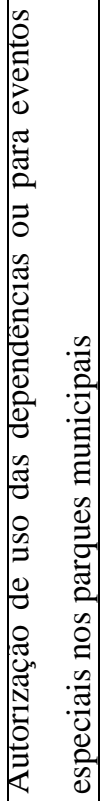 & 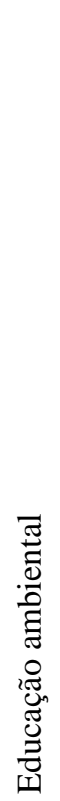 & & 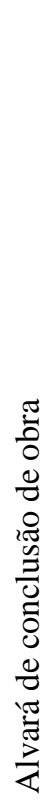 & 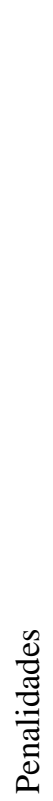 & 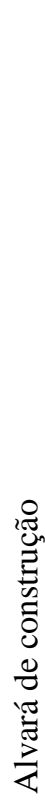 & 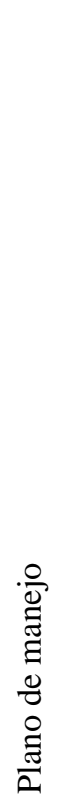 & 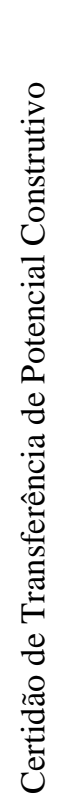 & 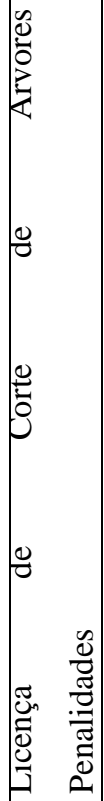 & 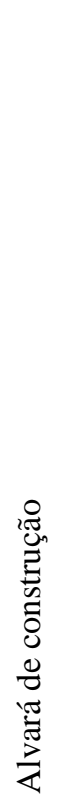 & 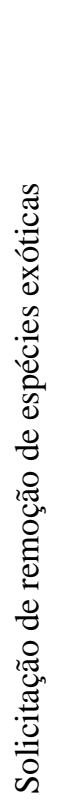 & 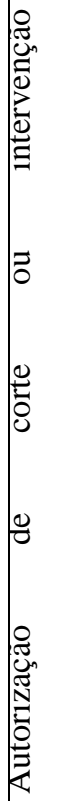 & 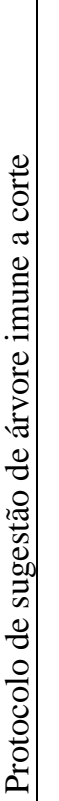 & 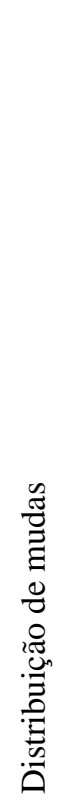 \\
\hline
\end{tabular}

Fonte: Elaborado com base em leis municipais (2016).

De qualquer maneira, os recursos de tecnologia da informação são subutilizados e não acrescentam novas contribuições ao planejamento da paisagem, pois apenas são referentes à execução mais ágil de serviços que já faziam parte do processo de gestão municipal, anteriores aos conceitos de cidade digital. Em contrapartida, as possibilidades de utilização de algumas tecnologias - como painéis eletrônicos e grupos de discussão, no processo de planejamento e avaliação da paisagem - constituiriam grandes oportunidades para a inclusão da percepção do usuário no sistema de conhecimento aplicável ao tratamento dessa temática (Quadro 7). 
Quadro 7: Possibilidades de aplicação da interface com o cidadão pelas leis intervenientes na composição e qualificação da paisagem de Curitiba.

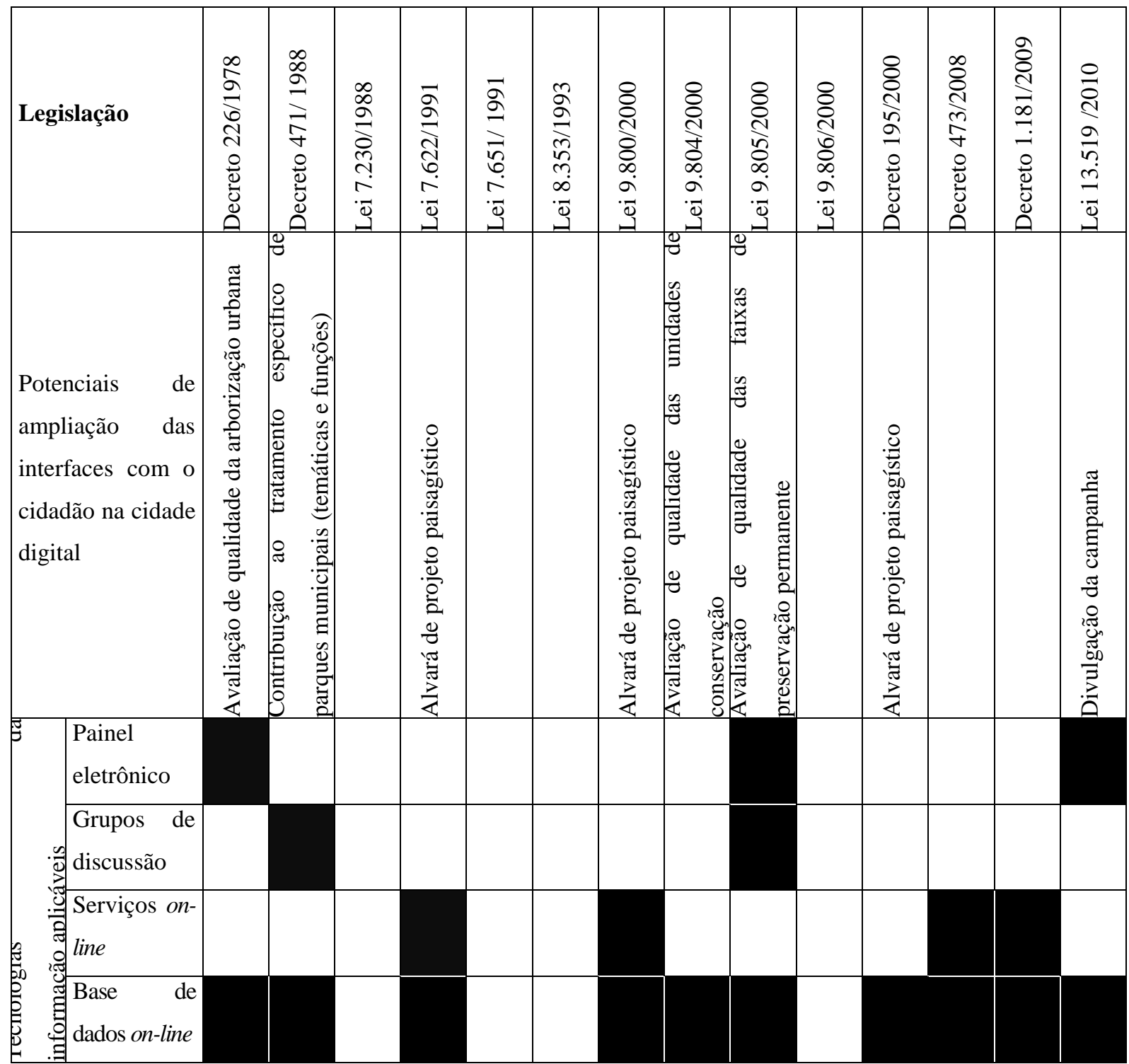

Fonte: Elaborado com base em leis municipais (2016) e nas tecnologias da informação indicadas por Cândido e Araújo (2003).

Notas:

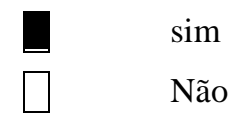

Dentro do escopo de cada norma analisada e da tecnologia disponível, observa-se uma oportunidade de maior envolvimento da população no planejamento da dimensão qualitativa dos espaços verdes. Esse processo pode ser viabilizado por meio de pesquisas perceptivas (painéis eletrônicos), de fóruns nas redes sociais ou de páginas institucionais (grupos de discussão), além de canais de trocas de serviços e dados. As 
Planejamento Participativo da Paisagem na Cidade Digital: Análise de Potencialidades Em Curitiba, Paraná

ferramentas disponíveis no ambiente digital permitem a reunião de interpretações pessoais - indispensáveis à qualificação paisagística (Hardt, 2004) - e a inclusão da perspectiva cognitiva nas decisões políticas que envolvem a paisagem (Cardoso \& Machado, 2008).

Os canais de comunicação na direção do cidadão para os organismos públicos também são potenciais para a complementação da base de dados necessária à sistematização dos parâmetros de qualificação das áreas verdes, por meio, por exemplo, de uploads de projetos paisagísticos e cadastros fotográficos (Quadro 8).

Quadro 8: Potencial de contribuição do cidadão para a base de dados de qualificação da paisagem de Curitiba.

\begin{tabular}{|c|c|c|c|}
\hline \multirow{2}{*}{\multicolumn{2}{|c|}{ Qualificação da área verde }} & \multicolumn{2}{|c|}{ Potencial de contribuição dos usuários via on-line } \\
\hline & & Quantitativo & Qualitativo \\
\hline \multirow{6}{*}{ Parâmetros } & Área (ha) & projetos paisagísticos & $\begin{array}{l}\text { percepção de qualidade quanto à suficiência } \\
\text { de área verdes }\end{array}$ \\
\hline & Variedade de espécies $\left(\mathrm{n}^{\circ}\right)$ & $\begin{array}{l}\text { projetos paisagísticos, } \\
\text { cadastros fotográficos }\end{array}$ & $\begin{array}{l}\text { percepção de qualidade quanto à suficiência } \\
\text { na variedade de espécies }\end{array}$ \\
\hline & Porte (h) & cadastros fotográficos & $\begin{array}{l}\text { percepção de qualidade quanto à suficiência } \\
\text { de árvores, arbustos e vegetação rasteira }\end{array}$ \\
\hline & Forma & projetos paisagísticos & $\begin{array}{l}\text { percepção de qualidade associada à } \\
\text { composição formal da vegetação }\end{array}$ \\
\hline & Cor & projetos paisagísticos & $\begin{array}{l}\text { percepção de qualidade associada à } \\
\text { composição formal da vegetação }\end{array}$ \\
\hline & Textura & projetos paisagísticos & $\begin{array}{l}\text { percepção de qualidade associada à } \\
\text { composição formal da vegetação }\end{array}$ \\
\hline
\end{tabular}

Fonte: Elaborado com base nos resultados anteriores.

A construção de uma base on-line de projetos paisagísticos, acompanhados de imagens e cadastros fotográficos, pode alimentar o sistema de informação da cidade. Então, torna-se factível, por meio de painéis eletrônicos, por exemplo, a medição da apreciação da população sobre as propostas paisagísticas para a cidade e a orientação dos gestores sobre os aspectos qualitativos das cenas urbanas que coincidem com os valores sociais de citadinos. Ressalte-se, porém, que importa a comunidade ser 
reconhecida pelo destaque estético das paisagens que a retrata (Cosgrove, 2006). As oportunidades da cidade digital permitem a efetividade desta representação, ao proporcionarem a inclusão da percepção individual e coletiva dos diferentes habitantes da paisagem no processo de qualificação dos espaços urbanizados (Dorigo e Ferreira, 2015).

\section{CONCLUSÃO}

O alcance do objetivo geral preconizado para esta pesquisa, vinculado à análise do potencial do planejamento participativo da paisagem na cidade digital, permite a assertiva da possibilidade de inclusão do citadino pelas tecnologias da informação. Esse processo, porém, deve ser desenvolvido tanto na direção da otimização das interfaces do setor público com o cidadão quanto no sentido oposto, de contribuição da população nos mecanismos de avaliação paisagística.

Não obstante o extenso aporte teórico sobre paisagem no âmbito da gestão municipal, ainda são raros os estudos sobre suas relações com cidades digitais, apesar da eventual aplicação de tecnologias de informação em procedimentos de qualificação de cenas urbanas.

Como opção metodológica, a adoção de Curitiba como objeto de estudo, com recorte das áreas verdes no planejamento municipal, revelou um amplo aparato legal para a tratativa da temática na administração pública. Todavia, diagnostica-se que o tema ainda é mais um conceito do que uma prática, por se encontrar disperso em diferentes campos de atuação da esfera governamental, não articulados com o intuito particular de valorizar os cenários urbanos.

Pela análise documental, restrita aos espaços verdes como componentes paisagísticos relevantes, depreende-se que a participação dos cidadãos por meio de ambientes virtuais ainda é insuficiente para o estabelecimento de cenários urbanizados como elos de conexão entre habitantes e território habitado na capital paranaense.

Os parâmetros quantitativos de diversas normas legais não incorporam outros de ordem cognitiva, nem estabelecem critérios de qualificação paisagística. Pode-se considerar, assim, que as relações identitárias que eventualmente são estabelecidas com 
as áreas verdes municipais são resultantes de um fluxo unidirecional da prefeitura para o cidadão, sendo gradativamente apropriadas pela população.

Igualmente, o ambiente das cidades digitais é uma oportunidade para o estabelecimento das necessárias interações entre os diferentes órgãos competentes, os usuários e a base de dados municipais, viabilizando e efetivando a paisagem como temática de gestão urbana, inclusive na sua dimensão imaterial.

As tecnologias da informação aplicáveis à inclusão do munícipe na qualificação das áreas verdes e de outros elementos paisagísticos de forma conjunta, especialmente como recursos de projetos de cidade digital, constituem caminhos para a consolidação de um sistema de conhecimento dedicado à prática do planejamento da paisagem.

O estudo documental relatado apontou que, sob a ótica estrita das variáveis analisadas, o planejamento participativo da paisagem em Curitiba ainda é quase inexistente, com instrumentos não interativos de interface com o cidadão. Apenas agilizando procedimentos burocráticos, são desconectados de uma base de dados que permita a inclusão dos usuários em um processo de troca de informações. Em contrapartida, a partir da legislação vigente, existem oportunidades de ampliação da participação do munícipe, quando se considera o ambiente da cidade digital e as tecnologias disponíveis na atualidade.

Por fim, cabe ressaltar que a análise apresentada foi limitada às diretrizes legais relativas às áreas verdes em Curitiba, sem a verificação da real implementação das leis em seu território. Destarte, estudos futuros poderão contemplar essa comparação, além de estender as avaliações para a legislação pertinente a outros componentes da paisagem e para a realidade de outras cidades. 


\section{REFERÊNCIAS}

Albertin, A. L. \& Albertin, R. M. de M. (2012). Dimensões do uso de tecnologia da informação: um instrumento de diagnóstico e análise. Revista de Administração Pública - RAP, Rio de Janeiro: Escola Brasileira de Administração Pública e de Empresas Ebrape - da Fundação Getúlio Vargas - FGV, vol. 46, n.1, pp.25-51, jan./fev.

Barz, E. L.; Boschilia, R.; Hladczuk, A. M. \& Sutil, M. S. (1997). História de Curitiba. Recuperado em 22 de novembro, 2012, de <http://www.casadamemoria.org.br/ index_historiadecuritiba.html>.

Besselaar, P. V. D. \& Beckers, D. (2009). Demographics and sociographics of the digital city. Recuperado em 2 de fevereiro, 2009, de <http://portal.acm.org/citation.cfm?id =701393>.

Cândido, G. A. \& Araújo, N. M. (2003). As tecnologias de informação como instrumento de viabilização da gestão do conhecimento através da montagem de mapas cognitivos. Ciência e Informação, Brasília: Instituto Brasileiro de Informação em Ciência e Tecnologia - IBICT, vol.32, n. 3, pp. 38-45, set./dez.

Cardoso, O. N. P. \& Machado, R. T. M. (2008). Gestão do conhecimento usando data mining: estudo de caso na Universidade Federal de Lavras. Revista de Administração Pública - RAP, Rio de Janeiro: Escola Brasileira de Administração Pública e de Empresas - Ebrape - da Fundação Getúlio Vargas - FGV vol.42, n. 3, pp. 495-528, maio/jun.

Cosgrove, D. (2006). Modernity, community and the landscape idea. Journal of Material Culture, London: University College London, vol.11, n. 1-2, pp. 49-66, jul.

Curitiba. (1975). Lei Municipal no 5.234, de 10 de dezembro de 1975, Modifica a Lei $\mathrm{n}^{\mathrm{o}}$ 4.199/72 [dispõe sobre o zoneamento urbano de Curitiba] e dá outras providências. Diário Oficial [do] Município de Curitiba, Poder Executivo, Curitiba, PR.

(1976). Decreto Municipal no 400, de 9 de julho de 1976, Regulamenta os Setores Especiais de Preservação de Fundos de Vale. Diário Oficial [do] Município de Curitiba, Poder Executivo, Curitiba, PR.

(1978). Decreto Municipal no 226, de 14 de março de 1978. Aprova o Plano de Arborização de Curitiba. Diário Oficial [do] Município de Curitiba, Poder Executivo, Curitiba, PR.

(1988a). Lei Municipal $\mathrm{n}^{\circ}$ 7.230, de 30 de agosto de 1988. Torna obrigatório o plantio de árvores, arbustos e vegetações rasteiras, nas faixas não edificáveis de fundos de vale. Diário Oficial [do] Município de Curitiba, Poder Executivo, Curitiba, PR. 
(1988b). Decreto Municipal no 471, de 27 de outubro de 1988. Dispõe sobre os parques municipais e dá outras providências. Diário Oficial [do] Município de Curitiba, Poder Executivo, Curitiba, PR.

(1991a). Lei Municipal $n^{\circ} 7.622$, de $1^{\circ}$ de abril de 1991. Dispõe sobre a utilização do recuo do alinhamento predial dos terrenos edificados como área verde. Diário Oficial [do] Município de Curitiba, Poder Executivo, Curitiba, PR.

(1991b). Lei Municipal $n^{\circ} 7.651$, de 14 de maio de 1991. Dispõe sobre a obrigatoriedade do plantio de árvores nos passeios para a expedição do certificado de conclusão de obra. Diário Oficial [do] Município de Curitiba, Poder Executivo, Curitiba, PR.

(1991c). Lei Municipal no 7.833, de 19 de dezembro de 1991. Dispõe sobre a política de proteção, conservação e recuperação do meio ambiente e dá outras providências. Diário Oficial [do] Município de Curitiba, Poder Executivo, Curitiba, PR.

(1993). Lei Municipal no 8.353, de 22 de dezembro de 1993. Dispõe sobre o monitoramento da vegetação arbórea e estímulos à preservação das áreas verdes no município de Curitiba. Diário Oficial [do] Município de Curitiba, Poder Executivo, Curitiba, PR.

(2000a). Lei Municipal no 9.800, de 3 de janeiro de 2000. Dispõe sobre o zoneamento, uso e ocupação do solo no município de Curitiba e dá outras providências. Diário Oficial [do] Município de Curitiba, Poder Executivo, Curitiba, PR.

(2000b). Lei Municipal $n^{\circ}$ 9.804, de 3 de janeiro de 2000. Cria o sistema de unidades de conservação do município de Curitiba e estabelece critérios e procedimentos para implantação de novas unidades de conservação. Diário Oficial [do] Município de Curitiba, Poder Executivo, Curitiba, PR.

(2000c). Lei Municipal $n^{\circ}$ 9.805, de 3 de janeiro de 2000. Cria o Setor Especial do Anel de Conservação Sanitário Ambiental e dá outras providências. Diário Oficial [do] Município de Curitiba, Poder Executivo, Curitiba, PR.

(2000d). Lei Municipal $n^{\circ}$ 9.806, de 3 de janeiro de 2000. Institui o Código Florestal do município de Curitiba, revoga as Leis $n^{\circ} 8.353 / 93$ e 8.436/94, e dá outras providências. Diário Oficial [do] Município de Curitiba, Poder Executivo, Curitiba, PR.

(2000e). Decreto Municipal $n^{\circ}$ 195, de 3 de abril de 2000. Dispõe sobre o Setor Especial Residencial - Áreas Verdes - CIC. Diário Oficial [do] Município de Curitiba, Poder Executivo, Curitiba, PR.

(2002). Decreto Municipal $n^{\circ}$ 673, de 18 de setembro de 2002. Cria o Setor Especial do Parque Natural Municipal Tanguá e dá outras providências. Diário Oficial [do] Município de Curitiba, Poder Executivo, Curitiba, PR. 
(2008). Decreto Municipal no 473, de 5 de junho de 2008. Define as espécies florestais consideradas como exóticas invasoras para o município de Curitiba e dá outras providências. Diário Oficial [do] Município de Curitiba, Poder Executivo, Curitiba, PR.

(2009). Decreto Municipal nº1.181, de 15 de setembro de 2009. Declara imune de corte as árvores que especifica e dá outras providências. Diário Oficial [do] Município de Curitiba, Poder Executivo, Curitiba, PR.

(2010). Lei Municipal no 13.519, de 17 de junho de 2010. Institui a campanha permanente de incentivo à arborização de ruas, praças e jardins de Curitiba, e dá outras providências. Diário Oficial [do] Município de Curitiba, Poder Executivo, Curitiba, PR.

. (2015). Lei Municipal $n^{\circ} 14.771$, de 17 de dezembro de 2015. Dispõe sobre a revisão do Plano Diretor de Curitiba de acordo com o disposto no artigo 40, $\S 3^{\circ}$, do Estatuto da Cidade, para orientação e controle do desenvolvimento integrado do Município e dá outras providências. Diário Oficial [do] Município de Curitiba, Poder Executivo, Curitiba, PR.

Dorigo, T. A. \& Ferreira, A. P. N. L. (2015). Contribuições da percepção ambiental de frequentadores sobre praças e parques no Brasil (2009-2013): revisão bibliográfica. Revista de Gestão Ambiental e Sustentabilidade - GeAS, São Paulo: Universidade Nove de Julho - Uninove, vol.4, n.3, pp. 31-45, set./dez.

Gil, A. C. (2008). Métodos e técnicas de pesquisa social (6a ed.). São Paulo: Atlas.

Guerreiro, E. P. (2006). Cidade digital: infoinclusão social e tecnologia em rede. São Paulo: Editora do Serviço Nacional de Aprendizagem Comercial de São Paulo - Senac São Paulo.

Haesbaert, R. (2004). O mito da desterritorialização: do "fim dos territórios" à multiterritorialidade. Rio de Janeiro: Bertrand Brasil.

Hardt, L. P. A. (2000). Subsídios à gestão da qualidade da paisagem urbana: aplicação a Curitiba, Paraná. Tese de doutorado em Engenharia Florestal, Universidade Federal do Paraná - UFPR, Curitiba, Paraná, Brasil.

Hardt, L. P. A. (2004). Ecologia da paisagem: fundamentos à gestão do espaço urbano. OLAM Ciência \& Tecnologia, vol.4, n.1, pp. 597-612.

IPPUC - Instituto de Pesquisa e Planejamento de Curitiba. (2016). Informando o cidadão. Recuperado em 9 de março, 2016, de <http://ippuc.org.br/default.php> .

Ishida, T. (2012). Activities and technologies in digital city Kyoto. Lecture Notes in Computer Science, State-of-the-Art Survey, 3081, 2004. Recuperado em 11 de setembro, 2012, de <http://www.digitalcity.gr.jp/DigitalCityKyoto20040601.pdf>. 
Lamas, J. M. R. G. (2014). Morfologia urbana e desenho da cidade (7a ed.). Porto: Fundação Calouste Gulbenkian; Fundação para a Ciência e a Tecnologia.

Leis Municipais. (2016). Leis ordinárias e decretos. Recuperado em 10 de maio, 2016, de <http://www.leismunicipais.com.br/legislacao-municipal-da-prefeitura-ecamara/5520/leis de-curitiba.html>.

Lynch, K. (2011). A imagem da cidade (3a ed.). Tradução de Jefferson Luiz Camargo. São Paulo: Martins Fontes.

Macedo, S. S. (2010). Paisagismo brasileiro na virada do século: 1990-2010. São Paulo: Editora da Universidade de São Paulo - Edusp.

Mendes, S. L.; Bottoli, L. M. \& Breda, D. G. (2010). Digital cities and open MANs: a new communications paradigm. IEEE Latin America Transactions, New York: Institute of Electrical and Electronics Engineers - IEEE, vol.8, n.4, pp. 394-402, aug.

Mitchell, W. J. T. (2002). Landscape and power (2a ed.). Chicago: University of Chicago Press.

Mossberger, K.; Tolbert, C. J. \& Franco, W. W. (2013). Digital cities: the internet and the geography of opportunity. Oxford: Oxford University Press.

Mossberger, K.; Tolbert, C. J. \& McNeal R. S. (2008). Digital citizenship: the internet, society, and participation. Cambridge, MA: Massachusetts Institute of Technology - MIT Press.

Nava, A. \& Dávila, I. (2005). M-government for digital cities: value added public services. In The Proceedings of the 1st European Mobile Government Conference, Brighton, UK: Mobile Government Consortium International, pp. 304-312.

O’Brien, J. A. (2011). Sistemas de informação e as decisões gerenciais na era da internet (3a ed.). Tradução de Cid K. Moreira. São Paulo: Saraiva.

Olwig, K. R. (2013). The law of landscape and the landscape of law: the things that matter. In Howard, P., Thompson, I. \& Waterton, E. (Ed.) The Routledge companion to landscape studies. Abingdon; New York: Routledge. pp.166-178.

Relph, E. (2008). Place and placelessness. Repr. London: Paperbach. 
Rezende, D. A. (2012a). Cidade digital estratégica: modelo e aplicação em um município paulista. Anais do VIII Simpósio Brasileiro de Sistemas de Informação, São Paulo: Universidade de São Paulo Campus Leste - USP Leste, pp.126-131. Recuperado em 24 de outubro, 2015, de <http://www.lbd.dcc.ufmg.br/bdbcomp/servlet/Autor? id $=17442>$.

(2012b). Planejamento de estratégias e informações municipais para cidade digital: guia para projetos em prefeituras e organizações públicas. São Paulo: Atlas.

Rezende, D. A. \& Abreu, A. F. (2013). Tecnologia da informação aplicada a sistemas de informação empresariais: o papel estratégico da informação e dos sistemas de informação nas empresas (9a ed.). São Paulo: Atlas.

Rossetti, A. G. \& Morales, A. T. (2007). O papel da tecnologia da informação na gestão do conhecimento. Ciência e Informação, Brasília: Instituto Brasileiro de Informação em Ciência e Tecnologia - IBICT, vol.36, n. 1, pp.124-135.

Secchi, L. (2009). Modelos organizacionais e reformas da administração pública. Revista de Administração Pública - RAP, Rio de Janeiro: Escola Brasileira de Administração Pública e de Empresas - EBRAPE - da Fundação Getúlio Vargas FGV, vol.43, n. 2, pp. 347-369. mar./abr.

Sgard, A. (2012). Le partage du paysage. Geography, Grenoble: Université de Grenoble, s.n., pp. 1-261.

Trindade, E. M. C. (1997). Cidade, homem e natureza: uma história das políticas ambientais de Curitiba. Curitiba: Universidade Livre do Meio Ambiente - Unilivre.

Tuan, Y. (2012). Topofilia: um estudo da percepção, atitudes e valores do meio ambiente. Londrina: Editora da Universidade Estadual de Londrina - Eduel.

Turban, E.; Rainer, R. K. \& Potter, R. E. (2007). Introdução a sistemas de informação: uma abordagem gerencial. Tradução de Daniel Vieira. Rio de Janeiro: Elsevier.

\section{AGRADECIMENTOS}

À Coordenação de Aperfeiçoamento de Pessoal de Nível Superior (Capes), ao Conselho Nacional de Desenvolvimento Científico e Tecnológico (CNPq) e à Fundação Araucária de Apoio ao Desenvolvimento Científico e Tecnológico do Estado do Paraná (FA), pelo apoio financeiro à pesquisa. 